\title{
Nutritional and Microbiota Analysis of Fresh Produce in Delhi and National Capital Region
}

\author{
Sujata Adhana ${ }^{1}$, Rajnish Kumar $^{2}$, Shvetambri Arora ${ }^{3}$, Uma Chaudhry ${ }^{4}$ and N. S. Abbas ${ }^{* 5}$ \\ ${ }^{1}$ Department of Biomedical Sciences, Bhaskaracharya College of Applied Sciences, \\ University of Delhi, New Delhi-110075, India \\ Email-sujataadhana02 [AT] gmail.com \\ ${ }^{2}$ Department of Biomedical Sciences, Bhaskaracharya College of Applied Sciences, \\ University of Delhi, New Delhi-110075, India \\ Email-rajnishbiochem [AT] gmail.com \\ ${ }^{3}$ Department of Biomedical Sciences, Bhaskaracharya College of Applied Sciences, \\ University of Delhi, New Delhi-110075, India \\ Email-shvetambribcas [AT] gmail.com \\ ${ }^{4}$ Department of Biomedical Sciences, Bhaskaracharya College of Applied Sciences, \\ University of Delhi, New Delhi-110075, India \\ Email-uma.chaudhry [AT] bcas.du.ac.in

\footnotetext{
$5 *$ Department of Botany, Bhaskaracharya College of Applied Sciences, University of Delhi, New Delhi-110075, India

*Corresponding author's email: dr.nsabbas [AT] bcas.du.ac.in
}

\begin{abstract}
Fresh produce available in an area is the major source of phytonutrients for healthy life. Decrease in the concentration of phytonutrients is directly linked to a range of health issues in terms of increase in the rate of infections. This study conducted on fresh produce available in Delhi and National Capital Region (NCR) on microbiological and nutritional analysis showed a significant increase in microbial load in fruits as they stay over the period of a week to fortnight at room temperature. A total of seven different types of fresh produce were procured for analysis. Out of them, lemon showed the lowest microbial count and sugar content and grapes showed highest microbial count and sugar content. Results were also compared with refrigerated and room temperature stored fruits. It was concluded that fresh fruits have more nutritive value than stored fruits (room and refrigerated). In this study, glucose content was determined by Fehling's titration and Ascorbic Acid by Dichlorophenolindophenol method. The microbial biota was assessed by serial dilution method for determining microbial load of different types of bacteria. Some of the fruits showed decrease in the nutritive value and correspondingly increase in the load of antibiotic resistant microbes during storage rendering them unfit for human consumption.
\end{abstract}

Keywords---- Fresh Produce, Ascorbic acid, Microbial count, Nutrition.

ABBREVIATIONS: NCR: National Capital Region, APHA: American Public Health Association, FDA: Food and Drug Association, FAO: Food and Agriculture Organization, CFU: Colony Forming Unit, DCPIP: Dichlorophenolindophenol, DF: Dilution Factor, PCA: Plate Count Agar

\section{INTRODUCTION}

Vitamin C chemically known as ascorbic acid is a water-soluble compound. It is a very essential nutrient as it can't be synthesized by human body [1]. It is found in many biological systems and foodstuffs like fresh vegetables and fruits. A moderate amount of ascorbic acid is sufficient for the repair of tissues. If the intake of vitamin $\mathrm{C}$ is increased due to some reason, it may cause renal problems and gastric irritation [2]. Ascorbic acid plays an important role in collagen biosynthesis, iron absorption, immune response activation, osteogenesis and is involved in wound healing. It also acts as a powerful antioxidant that fights against free-radical induced diseases. Different types of methods can be used for determining ascorbic acid like titrimetry, colorimetry, enzymatic method and high-performance liquid chromatography.

Glucose is an important ingredient of fruits and fruit products. It is the main sugar present in fruits. Glucose is often recommended for people with diabetes mellitus having hypoglycemia as it has a very low Glycemic Index (GI). GI is a ranking system for carbohydrates based on their effect on blood glucose level. Fehling's test is used to distinguish between 
functional groups of water-soluble aldehydes, ketones and as a monosaccharide's test. Fruits are an important source of nutrition and they are more nutritious and healthier, when eaten fresh. Fruits contain nutrients like minerals, proteins and antioxidants, which improve body's immunity, and also prevent heart diseases [3]. Fresh and refrigerated fruits have different nutritional values. This research study compares the nutritional values of fresh fruits, with refrigerated and room temperature stored fruits. According to research studies conducted, it was estimated that nutritional values of fruits decrease when they are preserved for more than a year [3]. In most cases, blanching leads to the loss of nutrients like vitamin-B and vitamin-C. Blanching is the process in which food is scalded in boiling water for some time and eventually plunged into iced water to decrease the microbial load. Blanching also affects fruit color, texture and flavor. The extent of nutrient loss of fruits, depends upon types and period of blanching. Generally, nutrient losses range from 10-80\%, with an average of around $50 \%[4,5]$.

It is also indicated that fresh and frozen fruits show very minute differences in nutritional values. Some people use hand harvested produce to avoid the effects of storage and transport while as others procure them directly from supermarkets. Food processing such as heating at high temperature, drying, canning etc. cause major nutrient loss. It is also f reported that nutritional values of fresh and frozen fruits are the same as nutritional values remain preserved in frozen fruits [6].

Fresh fruits and vegetables of high-quality are excellent sources of nutrients such as vitamins, micronutrients and fiber for health and fitness. Balanced diet, comprising of fruits and vegetables are important to save us from diseases [7]. Fresh fruits promote fitness however they harbor a huge variety of microbial contaminants, hence undermining their dietary and health advantages and increasing outbreak of infections [8]. Health advisors recommend that increasing intake of tropical fruits promotes and maintains good health $[9,10]$. Fruits and vegetable vendors normally do not follow standard hygienic practices due to lack of storage facilities. They carry fruits and vegetables in open carts, trays, sacks, etc. that unintentionally contaminates the fresh produce and increases the possibility of transmitting food-borne illness. Therefore, to retain the maximum nutritive value of fresh fruits and correspondingly to minimize the risk of infections, the transport and storage facilities must be standardized.

Microbiological risk assessment is a rising issue for the safety of food and water supplies. Various associations have proposed that microbiological chance evaluation ought to be completed to reduce food-borne sickness. The present study aims to get baseline data of fresh produce of fruits to analyze their microbial load by serial dilution method and the nutritional status of sugar and ascorbic acid by Fehling titration and DCPIP method respectively in different storage conditions. The results of microbial load and nutritional status of fresh, refrigerated and stored (room temperature) fruits have been compared and analyzed for their utility.

\section{MATERIALS AND METHODS}

\subsection{Samples Collection:}

Fresh fruits were purchased from local market of Delhi and NCR. Before the extraction procedure, all the fruits samples were thoroughly washed with distilled water to remove contaminants. Glucose and ascorbic acid contents in the samples were determined on the same day of purchase to avoid the decomposition of sugars and instability of vitamin C. A total of twenty-one samples comprising of seven types of fruits at three different storage conditions were collected [Malus pumila (Apple), Citrus sinensis (Orange), Citrus limon (Lemon), Actinidia deliciosa (Kiwi), Psidium guajava (Guava), Vitis vinifera (Black grapes and Green grapes variety)]. All the samples were collected in sterilized containers and examined in the Research laboratory, Department of Biomedical Sciences, Bhaskaracharya College of Applied Sciences, University of Delhi, Delhi, India.

\subsection{Glucose Estimation:}

\section{Quantitative Estimation of Glucose by Titrimetric Analysis:}

Glucose was quantified by Fehling titration [11]. Fehling's solution-A was prepared by dissolving $69.2 \mathrm{~g}$ of pure $\mathrm{CuSO} 4.5 \mathrm{H} 2 \mathrm{O}$ in distilled water and the final volume was made $1000 \mathrm{ml}$. Fehling's solution-B was prepared by dissolving $140 \mathrm{~g} \mathrm{NaOH}$ and $346 \mathrm{~g}$ Rochelle salt (Sodium Potassium Tartrate) in distilled water and the final volume was made 1000 $\mathrm{ml} .1 \%$ methylene blue solution was used as an indicator.

Glucose is reduced by freshly prepared Fehling solution [mixture of Fehling solution A and Fehling solution B in 1:1 ratio]. Fifty gm of each fruit sample was ground separately and distilled water was added to make final volume $250 \mathrm{ml}$. Fruit extract was centrifuged at $5000 \mathrm{rpm}$ for 5 minutes to get a clear solution. Clear supernatant (fruit extract) was used for titration. The burette was filled with fruit extract and $10 \mathrm{ml}$ of pre-heated $\left(70^{\circ} \mathrm{C}\right)$ Fehling solution was taken in a conical flask. The fruit extract was titrated drop wise against Fehling solution until blue color of Fehling solution disappeared and red precipitate of $\mathrm{Cu}_{2} \mathrm{O}$ began to appear. Throughout the titration, the temperature of the solution in conical flask was maintained $70^{\circ} \mathrm{C}$. Methylene blue indicator ( 5 drops) was added to the solution in flask to detect the endpoint accurately. Similarly, titration was repeated with each fruit extract to get five concordant readings. The volume of fruit extract used for reducing Fehling solution was used to calculate the amount of sugars present in fruit extract. 
Total percentage of sugars in fruit extracts was calculated using the formula:

mg reducing sugars per $100 \mathrm{~mL}=$ FactorX100/Titre

$\%$ Total sugar $=\mathrm{mg}$ of sugar in $100 \mathrm{ml}$ fruit extract $\mathrm{X}$ dilution factor X $100 /$ weight of the sample X1000 [11]

Factor was calculated from the pearson table [12]

\subsection{Quantitative Estimation of Ascorbic acid:}

Ascorbic acid content was quantified by titrimetric analysis [13,14]. It is a strong reducing agent and it reduces 2,6 dichlorophenolindophenol (DCPIP)- blue coloured dye to colourless form and it gets converted to dehydroascorbic acid. The dye in this titration is coloured in the oxidized form and colourless in the reduced form. Also, the dye is pink in acidic solution and blue in alkaline solution. DCPIP (titrant) was standardized by titration with standard ascorbic acid solution $(0.05 \mathrm{mg} / \mathrm{ml})$. The ascorbic acid content equivalent to $1 \mathrm{ml}$ DCPIP used for titration was $0.05 \mathrm{mg}$. Fruit sample (20 gm) was ground in 4\% Oxalic acid solution and total volume was made to $100 \mathrm{ml}$. Fruit extract was centrifuged at $5000 \mathrm{rpm}$ for 5 minutes to get a clear solution. The burette was filled with $0.1 \%$ DCPIP. Fruit extract (10 ml) was taken in a conical flask and titrated against $0.1 \%$ DCPIP solution. The DCPIP was then added drop wise into the $10 \mathrm{ml}$ fruit extract taken in conical flask with gentle shaking till a light pink colour (end point) appeared which persisted for 30 seconds and the volume of DCPIP used was recorded. The volume of DCPIP consumed for titration was used to calculate the amount of ascorbic acid present in the fruit extract. The titration was repeated with each fruit extract to get five concordant readings. The concentration of ascorbic acid in fruits was calculated and expressed in $\mathrm{mg}$ of ascorbic acid/100gm of fruit sample.

$\mathrm{mg}$ of ascorbic acid/100gm of fruit sample $=$ Volume of DCPIP used for titration X $0.05 \mathrm{X}$ dilution factor X100 X 5

\subsection{Microbiological Analysis:}

\subsubsection{Total Viable Count:}

Total viable count of microbial colonies was estimated by serial dilution using Plate Count Agar method. Ten gm of fruit sample was added into $90 \mathrm{ml}$ of two percent autoclaved peptone solution. This mixture was incubated at $37^{\circ} \mathrm{C}$ for an hour. This served as a stock solution and was used for serial dilution. Five test tubes were labelled as $10^{-1}$ to $10^{-5}$. In each test tube, ${ }^{9} \mathrm{ml}$ of two percent peptone solution was added. One ml of stock solution was pipetted out and was transferred into the first test tube labelled as $10^{-1}$ and shaken well. From the test tube labelled as $10^{-1}, 1 \mathrm{ml}$ solution was pipetted out and added into the test tube labelled as $10^{-2}$. Likewise, this process was repeated till the test tube number $10^{-5}$. Plate count agar media was used for counting the colonies. Five petri dishes containing PCA were labelled corresponding to the test tube like $10^{-1}$ to $10^{-5}$. $0.1 \mathrm{ml}$ was taken from test tube labelled as $10^{-1}$ to $10^{-5}$ and added to corresponding PCA plates labeled accordingly by spread plate method. All PCA plates were incubated at $37^{\circ} \mathrm{C}$ for $24 \mathrm{hrs}$. After incubation, colonies were counted and results were recorded as $\log \mathrm{CFU} / \mathrm{ml}$.

$\mathrm{CFU} / \mathrm{ml}=($ No. of colonies $\mathrm{x}$ Dilution Factor $) /$ volume of culture plate.

Total viable count of microbial colonies of all samples (fruit juice) was determined by plate count as described by American Public Health Association (APHA) [15, 16, 17] and Food and Drug Association FDA [18] using the Plate Count Agar medium (Hi Media, M091).

\section{RESULTS}

Present study deals with the estimation of glucose and ascorbic acid content (Table-1 and Table-2) in fruits. The results show that grapes contained highest glucose content $(7.73 \pm 0.32 \mathrm{~g} / 100 \mathrm{gm})$ and lemon the lowest glucose content $(0.13 \pm 0.05$ $\mathrm{g} / 100 \mathrm{gm})$, ascorbic acid content was the highest in lemon $(285.13 \pm 0.56 \mathrm{mg} / 100 \mathrm{~g})$ and kiwi $(151.17 \pm 2.3 \mathrm{mg} / 100 \mathrm{~g})$ and lowest in apple $(16.59 \pm 1.48 \mathrm{mg} / 100 \mathrm{~g})$. It has been found that the ascorbic acid content was higher in green grapes $(76.82 \pm 1.46 \mathrm{mg} / 100 \mathrm{~g})$ in comparison to black grapes $(61.72 \pm 0.63 \mathrm{mg} / 100 \mathrm{~g})$. It was also observed that sugar and ascorbic acid content decreased in most of the fruits stored at room temperature where as less significant differences were observed in fruits stored in refrigerator (Figure 1 and 2).

Microbial count ranged from 6.47 to $7.07 \log$ CFU/ml and lemon had the lowest microbial count (6.47 log CFU/ml) while grapes had the highest microbial load $(7.07 \log \mathrm{CFU} / \mathrm{ml})$. The microbial load was high when fruits were stored at room temperature whereas very little difference was observed in refrigerated fruits (Table $3 \&$ Figure 3 ). The increased microbial load contamination was observed in fruits due to unhygienic transportation, storage, handling and processing (Figure 4). 
Table 1: Amount of glucose $(\mathrm{g} / 100 \mathrm{gm})$ in fresh, refrigerated and room temperature stored fruits (Mean \pm S.D)

\begin{tabular}{lccc}
\hline \multicolumn{1}{c}{ Fruits } & Fresh & Refrigerated & Room Temperature \\
\hline Malus pumila (Apple) & $4.66 \pm 0.15$ & $4.16 \pm 0.10$ & $3.2 \pm 0.150$ \\
Citrus sinensis (Orange) & $2.73 \pm 0.32$ & $2.36 \pm 0.32$ & $1.53 \pm 0.35$ \\
Citrus limon (Lemon) & $0.13 \pm 0.05$ & $0.16 \pm 0.05$ & $0.06 \pm 0.05$ \\
Actinidia deliciosa (Kiwi) & $3.23 \pm 0.15$ & $3.13 \pm 0.15$ & $2.26 \pm 0.20$ \\
Psidium guajava (Guava) & $3.03 \pm 0.20$ & $2.67 \pm 0.50$ & $4.13 \pm 0.35$ \\
Vitis vinifera (B. grapes) & $7.73 \pm 0.32$ & $7.50 \pm 0.10$ & $6.36 \pm 0.32$ \\
Vitis vinifera (G. grapes) & $5.70 \pm 0.20$ & $5.46 \pm 0.25$ & $5.10 \pm 0.10$ \\
\hline
\end{tabular}

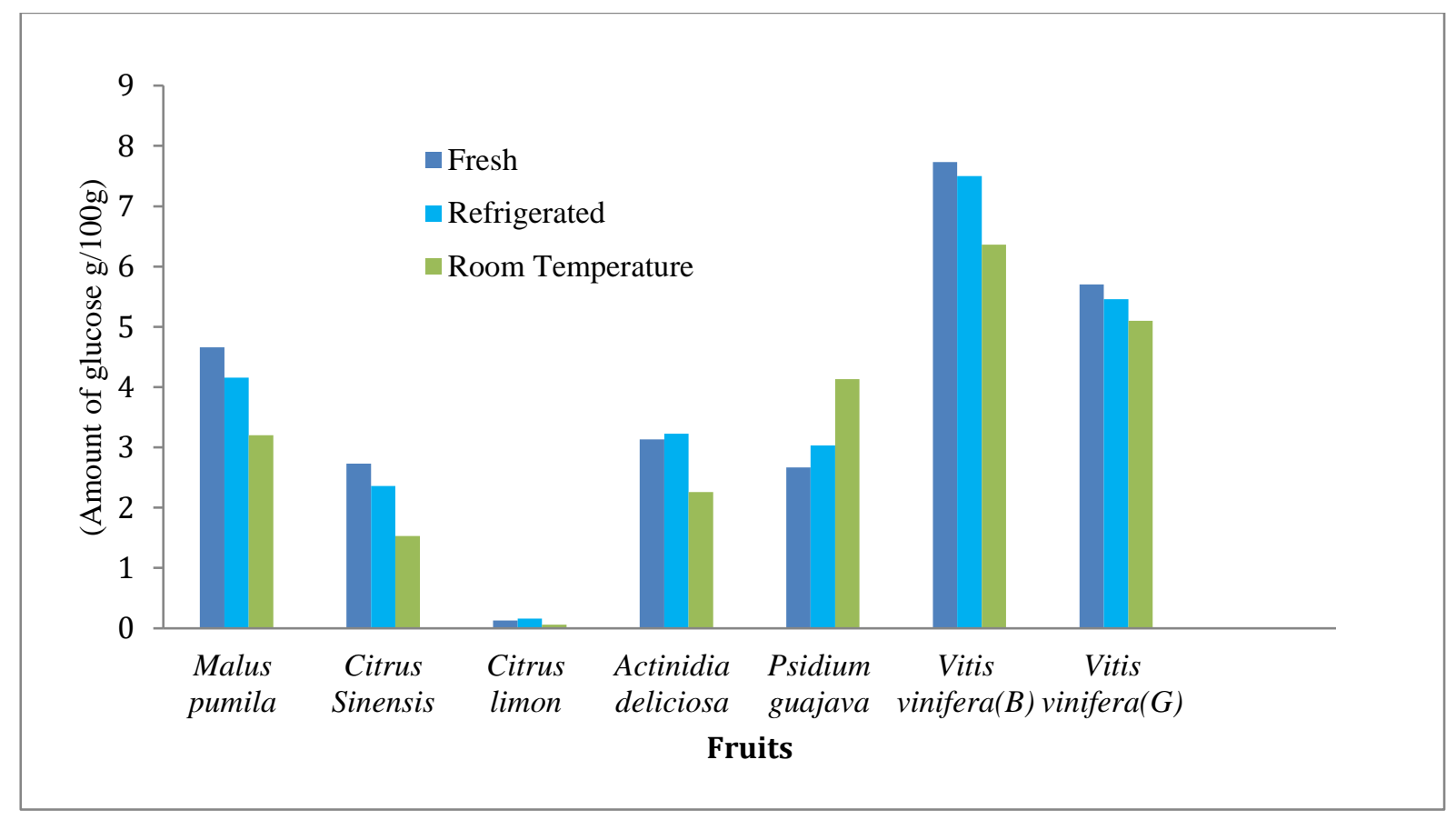

Figure 1: The Amount of glucose in fresh, refrigerated and room temperature stored fruits.

Abbreviations: B. - Black, G. - Green 
Table 2: Amount of ascorbic acid (mg/100g) in fresh, refrigerated and room temperature stored fruits (Mean \pm SD).

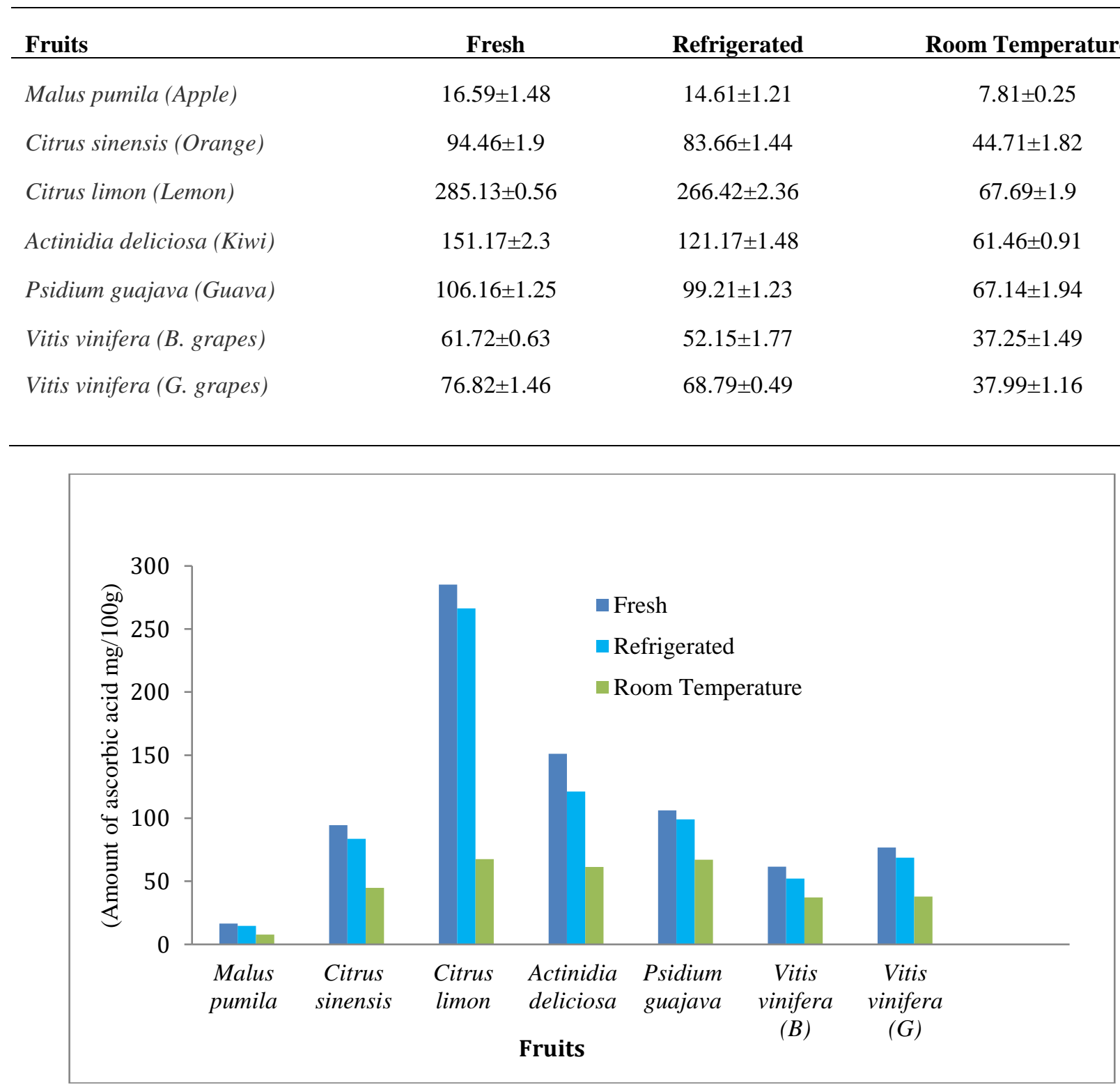

Figure 2: Comparison of amount of ascorbic acid in fresh refrigerated and room temperature stored fruits.

Table 3: Total plate count $(\log \mathrm{CFU} / \mathrm{ml})$ of microbial load in fresh, refrigerated and room temperature stored fruits

\begin{tabular}{lccc}
\multicolumn{1}{c}{ Fruits } & Fresh & Refrigerated & Room Temperature \\
\hline Malus pumila (Apple) & 6.77 & 6.79 & 6.97 \\
Citrus sinensis (Orange) & 6.66 & 6.69 & 6.91 \\
Citrus limon (Lemon) & 6.47 & 6.6 & 6.77 \\
Actinidia deliciosa (Kiwi) & 6.69 & 6.68 & 6.88 \\
Psidium guajava (Guava) & 6.66 & 6.74 & 6.98 \\
Vitis vinifera (B. grapes) & 7.07 & 7.00 & 7.17 \\
Vitis vinifera (G. grapes) & 7.00 & 7.04 & 7.11 \\
\hline
\end{tabular}




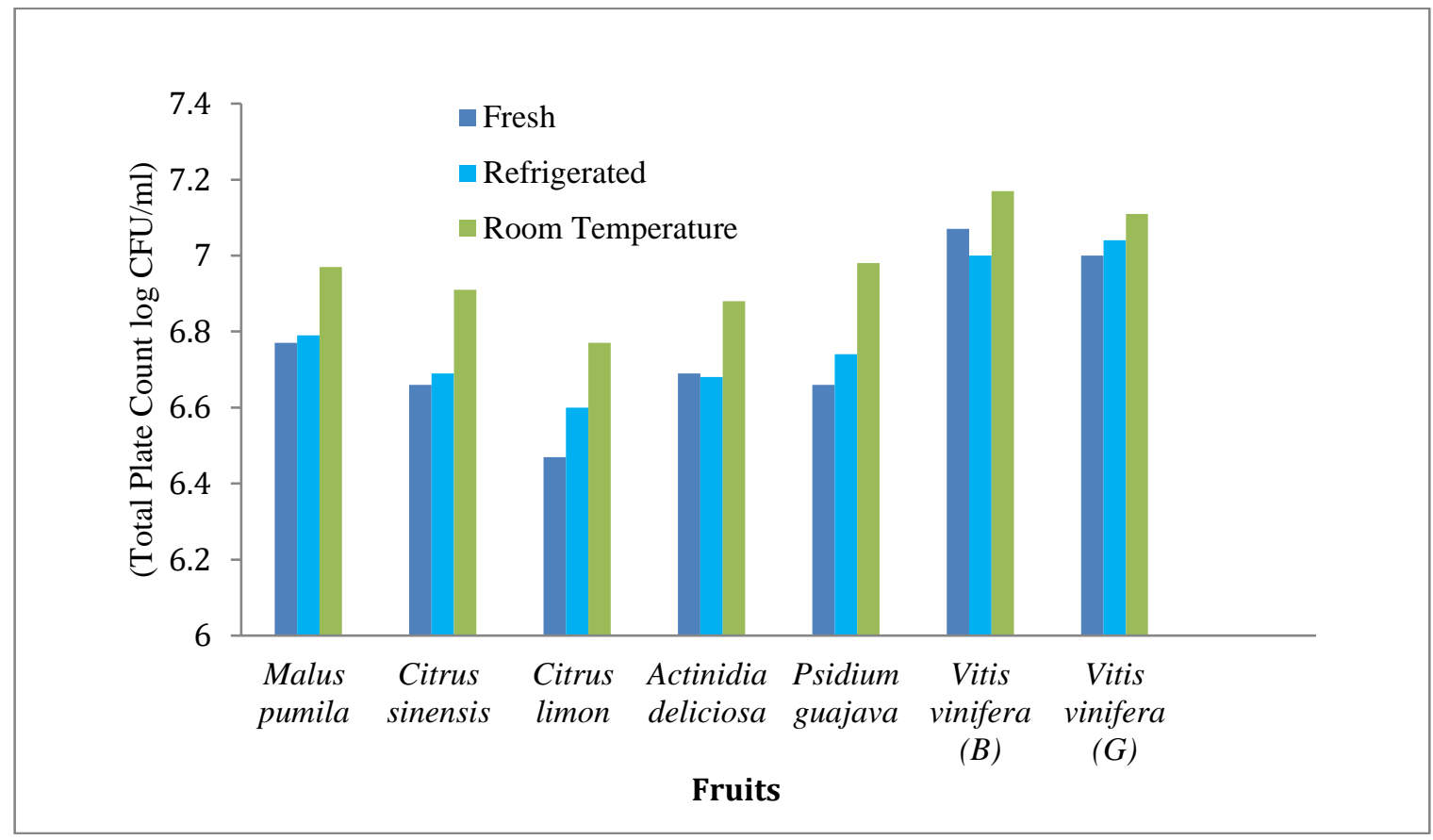

Figure 3: Comparison of microbial load in fresh refrigerated and room temperature stored fruits.

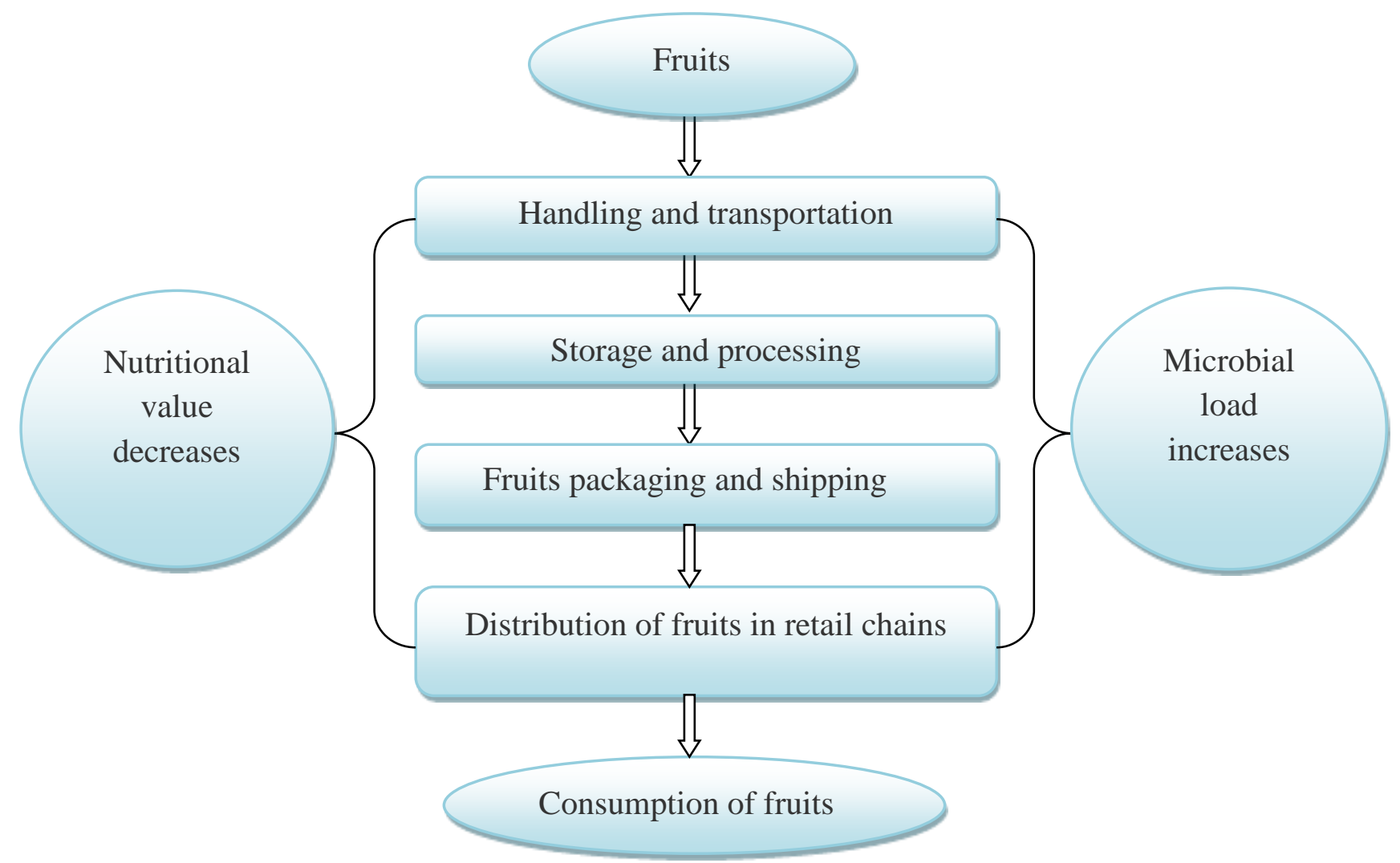

Figure. 4: Processing of fruits from growers to fruit seller for consumption. 


\section{DISCUSSION}

All over the world fruit farming for its import and export plays an important role in the economy. Fruits are essential dietary attributes as they are rich source of a variety of organic compounds. They are transported within the country by various means and carried by hawkers to various places for sale. In the present study, the microbial load as well as nutrition status of different fruits have been compared and it has been found that glucose content was highest in black grapes and lowest in lemon. It has been reported that both the green and black grapes have same amount of ascorbic acid content [14]. However, the present studies showed that green grapes are better source of ascorbic acid than black grapes, which clearly support strong antioxidant potential of green grapes. The results indicate that fresh fruits have the highest amount of nutritional value compared to refrigerated fruits. There are reports confirming that there were less significant differences among nutritional status of fresh and refrigerated fruits [4] but nutritional status of ascorbic acid of some fruits decreases during storage [19]. It has also been observed that microbial load increases in fruits stored at room temperature. There were less significant differences reported in the microbial load of fresh produce and refrigerated fruits. Therefore, it is evident that temperature plays a crucial role for increased microbial load during storage of fruits at room temperature.

According to The United Nations Food and Agriculture Organization (FAO) 2016 many people in the world are suffering from chronic malnutrition due to inadequate intake of nutritious food. The fruits are occupying a large percentage of daily food items of the present - day civilized state clearly due to their super meal values. Food plays an important role in everyone's life. Usually consumers expect that food like fruit, fruit juices and vegetables, etc. should be of good quality and full of nutrients. If the quality of the dietary products is not appropriate as per the guidelines of Food and Drug Administration (FDA) they will pose undesirable health risk to human life.

In the present study quality assessment of fruits was successfully checked by titrimetric analysis. An overall correlation was confirmed between microbial load and storage of fruits, as microbial load increased during room temperature storage. It is evident from the table-3 that lemon has highest ascorbic acid content and lowest microbial load. The high microbial count present on fruits is a direct correlation with the quality of the cultivation, water, harvesting, transportation, storage (Figure-4) and processing [20, 21, 22]. Hence, individual fruit growers and sellers should take precautions to maintain quality of fruits such as nutritional value and microbial load.

\section{CONCLUSION}

Storage conditions play a crucial role in maintaining the phytonutrients of fresh produce. It has been confirmed in the present study that nutritional value of fresh fruits, reduces on storage, as most of the samples showed contamination with different types of microorganisms. One of the reasons for loss of nutritional value can be poor handling of fruits during transportation and storage. Freshly produced fruits are not only important for boosting the immunity but are also source of nutritional security. Further research is required to explore the health threats posed by increased microbial load of fruits during various storage practices. Also, there is need to explore the benefits of fruits as well as the use of their functional components in the development of various value-added food products and supplements. The market for fruits and their products could therefore be improved significantly in future for decreasing disease burdens as nutrients play an important role in combating diseases as well as pandemics such as COVID 19 [23].

\section{FINANCIAL SUPPORT}

Authors are grateful to University Grant Commission (UGC), Council of Scientific and Industrial Research (CSIR) and Indian Council of Medical Research (ICMR) for providing financial assistance.

\section{CONFLICTS OF INTEREST}

The authors declared that there is no conflict of interest.

\section{ACKNOWLEDGEMENT}

Authors are thankful to Dr. Balaram Pani, Principal, Bhaskaracharya College of Applied Sciences, University of Delhi for providing institutional facilities to carry out experimental studies.

\section{REFERENCES}

[1]. S.Vitor, J. Eulogio. Determination of Vitamin C in Food: Current state of method validation. 1369: pp1-11, 2014.

[2]. Pisoschi, A. M., Danet, A. F. \& Kalinowski, S. Ascorbic Acid determination in commercial fruit juice samples by cyclic

voltammetry. J. Autom. Methods Manag. Chem. 2008: pp1-8, 2008.

[3]. Griep Oude M.L., Geleijnse M.J., Kromhout.D.et al. Raw and processed fruits and vegetables consumption and 10year

coronary Heart Disease incidence in a population-Based cohort study in the Netherlands. 15: pp2280-2286, 2010.

[4]. Shofian, M.N., Hamid A.A.et al. Effect of Freeze-Drying on the Antioxidant Compounds and Antioxidant Activity of Selected Tropical Fruits. Int J Mol Sci.12(7):4678-92, 2011. 
[5]. Miller R.S., Knudson A. Nutritional and cost comparisons of select canned, frozen, and fresh fruits and vegetables. Lifestyle

Medicine.8: pp430-437, 2014.

[6]. Linshan L., Ronald P. et al. Selected nutrient analyses of fresh, fresh-stored, and frozen fruits and vegetables.

Journal of

Food Composition and Analysis. 59:pp8-17, 2017.

[7]. Huaidong D., Liming L. et al. Fresh Fruit Consumption and Major Cardiovascular Disease in China. N Engl J Med. 374:

pp1332-1343, 2016.

[8]. Luna J.J., Arenas M.M. et al. The Role of Pathogenic E. coli in Fresh Vegetables: Behavior, Contamination Factors, and

Preventive Measures. Int J Microbial. 2019; pp1-10, 2019.

[9]. Lim YY, Lim TT, Tee JJ. Antioxidant properties of several tropical fruits: A comparative study. Food Chem. 103:1003-

1008, 2007.

[10]. Wong SP, Leong LP, Koh JHW. Antioxidant activities of aqueous extracts of selected plants. Food Chem. 99:775783 ,

2006.

[11]. A. Lokonuzzaman, I. Nazrul, I.Saidul. A Quantitative Estimation of the Amount of Sugar in Fruits Jam Available in Bangladesh. Science Journal of Analytical Chemistry. 3(5): 52-55, 2015.

[12]. Pearson, D. The Chemical Analysis of Foods. $7^{\text {th }}$ Edition. Churchill Livingstone. Edinburgh London and New York.1976 : 143-158, 2015.

[13]. Rekha, C., Poornim, G., Manasa, M., Abhipsa, V., Devi, J., Kumar, H., Kekuda, T. Ascorbic acid, total phenol content and antioxidant activity of fresh juices of four ripe and unripe citrus fruits. Chem. Sci. Trans. 1(2): 303-310, 2012.

[14]. B.Deekshika, B.L.Praveena. Estimation of ascorbic acid content in fruits \& vegetables - A theoretical assessment of Vitamin C activity. International Journal of Current Microbiology and Applied Sciences. 4(1):96-99, 2015.

[15]. Wehr H. M. and Frank J. H. Standard Methods for the Microbiological Examination of Dairy Products. $17^{\text {th }}$ Ed. APHA

Inc. Washington. DC. 2004.

[16] Baird R.B., Eaton A.D., and Rice E.W. Standard Methods for the Examination of Water and Wastewater.23 ${ }^{\text {rd }}$ ed. APHA. Washington. D.C. 2015.

[17]. Salfinger Y., and Tortorello M.L. Compendium of Methods for the Microbiological Examination of Foods. $5^{\text {th }}$ Ed. American Public Health Association. Washington. D.C. 2015.

[18]. FDA Bacteriological Analytical Manual. 18 ${ }^{\text {th }}$ Ed. AOAC, Washington. DC. 2005.

[19]. Ajibola V.O., Babatunde O.A. et al. The Effect of Storage Method on the Vitamin C Content in Some Tropical Fruit Juices. Trends in Applied Sciences Research, 4: 79-84, 2009.

[20]. R.C. Joy, B.M.Christine, B.M.Diane. Nutritional comparison of fresh, frozen, and canned fruits and vegetables II, vitaminA and carotenoids, vitamin E, minerals and fiber. Science of food and Agriculture. 87:1185-1196, 2007.

[21]. Ray B, Bhunia AK. Fundamental Food Microbiology. $4^{\text {th }}$ Ed. CRC Press. USA.492, 2007.

[22]. Lynette M., Deborah M., Martha CM, Juan A., Lee J., Brenda M. and Christine M. A field study of the microbiological quality of fresh produce. Journal of food protection. 68(9):1840 -1847, 2005.

[23.] Rishi P., Thakur K., Vij S., Rishi L., Singh A., Kaur IP., Patel SKS., Lee JK., Kalia VC. Diet, Gut Microbiota and COVID-19. Indian Journal of Microbiology.60(4): 420-429, 2020. 